\title{
TEMPO DE USO AGRÍCOLA E PROPRIEDADES QUÍMICAS DE DOIS LATOSSOLOS DO PLANALTO MÉDIO DO RIO GRANDE DO SUL ${ }^{(1)}$
}

\author{
E. PERIN (2), C. A. CERETTA ${ }^{(3)} \&$ E. KLAMT $^{(4)}$
}

\begin{abstract}
RESUMO
Os Latossolos, que predominam na região do Planalto Médio do Rio Grande do Sul sob vegetação de mata, foram incorporados ao uso agrícola a partir de 1920, enquanto os solos sob vegetação de campo foram explorados a partir da década de 1960. Estes solos sofreram alterações em suas propriedades químicas com o intenso uso agrícola, principalmente com culturas anuais como soja e milho. Este estudo teve como objetivo avaliar a influência do tempo de uso agrícola sobre propriedades químicas de dois Latossolos, no município de Fortaleza dos Valos (RS). Coletaram-se amostras de perfis de um Latossolo Vermelho distrófico típico (LVd) textura argilosa e de Latossolo Vermelho distrófico típico (LVd) textura média, sob cobertura vegetal natural de floresta e campo, respectivamente, em situação de topo de coxilha e de perfis destes solos sob uso agrícola por períodos que variaram de oito até mais de 33 anos. Foram determinados os teores de argila, matéria orgânica, $\mathrm{P}$ e K disponíveis e totais, $\mathrm{Ca}, \mathrm{Mg}$ e Al trocáveis e $\mathrm{pH}$. Calculou-se a saturação por bases (V) e por alumínio $(m)$. Os resultados mostraram que a diminuição no teor de matéria orgânica do solo com o tempo de uso agrícola foi perceptível, quando originalmente os solos eram de florestas, enquanto em solos de campo nativo o uso agrícola promoveu acrésci mo no teor de matéria orgânica. Nutrientes como Ca e Mg tiveram incremento no solo com o tempo de uso agrícola, ao contrário do Al, que diminuiu seu teor e saturação em profundidade. Por essa razão, os perfis que apresentavam caráter álico sob vegetação nativa passaram a ser distrófi cos quando com mais tempo de uso agrícola. Com o tempo de uso agrícola os incrementos de $P$ total foram evidentes nos horizontes superficiais, enquanto os incrementos de $\mathrm{K}$ total também ocorreram em profundidade.
\end{abstract}

Termos de indexação: uso do solo, matéria orgânica, nutrientes.

(1) Parte da Tese de Mestrado do primeiro autor junto ao Programa de Pós-graduação em Agronomia da Universidade Federal de Santa Maria - UFSM. Recebido para publicação em dezembro de 2001 e aprovado em maio de 2003.

(2) Engenheiro-Agrônomo, EMATER-PR. Rua PresidenteKennedy 1493, CEP 85640-000 Ampére(PR). E-mail: perin@ampernet.com.br

(3) Professor Titular do Departamento de Solos da Universidade Federal de Santa Maria - UFSM. CEP 97105-900 Santa Maria (RS). Bolsista do CNPq. E-mail: ceretta@ccr.ufsm.br

(4) Professor Titular Aposentado, Departamento de Solos, Universidade Federal do Rio Grande do Sul - UFRGS. CEP $90001-970$ Porto Alegre (RS). E-mail: fklamt@zaz.com.br 


\title{
SUMMARY: TIME OF AGRICULTURAL USE AND CHEMICAL PROPERTIES OF TWO FERRALSOLS IN THE PLANALTO MÉDIO REGION OF THE STATE OF RIO GRANDE DO SUL, BRAZIL
}

\begin{abstract}
From 1920 on, Ferral sols of the Planalto Médio regi on in the State of Rio Grande do Sul, Brazil, originally under forest vegetati on, were converted into agricultural land, while the same soils under grassland were converted in the 1960-ies. Thereafter, chemical soil properties were affected by intense cropping, mainly of soybean and corn. To evaluate how the time of agricultural land use affected two Ferralsols in theF ortaleza dos Valos county, State of Rio Grande do Sul, pedon samples of a clay textured dystrophic Red Latosol and a medium textured dystrophic Red Latosol werecollected under forest and grassland vegetation, respectively, on the top of the landscape and from soils under agricultural cultivation for eight to over 33 years. Concentrations of clay and organic matter; availableand total $\mathrm{P}$ and $\mathrm{K}$; exchangeable Ca, $\mathrm{Mg}$ and $\mathrm{Al}$; and pH weredetermined. Base (V\%) and al umi nium (m\%) saturation were calculated. Where the soil had been forested the organic matter content decreased after longer periods of agricultural use. On the other hand, the organic matter content increased as the time of agricultural use increased where the soil vegetation had been native grass. $\mathrm{Ca}+\mathrm{Mg}$ contents increased while Al content and saturation decreased with the time of agricultural use Originally Al-saturated soils under native vegetation gradually turned into soils with less than $50 \%$ of base saturation through theagricultural use The total soil P increased notably in the surface horizons, while the total soil $\mathrm{K}$ also increased in deeper layers.

Index terms: soil use, organic matter, nutrients.
\end{abstract}

\section{INTRODUÇÃO}

A vegetação original em Latossolos Vermelhos da região do Planalto M édio do estado do Rio Grande do Sul era de floresta subcaducifólia e de campo subúmido (Pampas). Nas condições naturais, estes solos são ácidos e apresentam teores baixos e médios de $\mathrm{Ca}, \mathrm{Mg}, \mathrm{K}$, soma e saturação por bases, que diminuem com a profundidade, enquanto os teores trocáveis e a saturação por Al são crescentes em profundidade (Brasil, 1973). Essa distribuição dos elementos em profundidade está relacionada com sua dinâmica através do ciclo biológico.

O desmatamento, queima e cultivo agrícola em áreas de floresta, com exportação contínua de nutrientes, começou no início do século XX pelos imigrantes europeus, enquanto as áreas de campo foram incorporadas ao uso agrícola a partir da década de 60, com a introdução da motomecanização e a recuperação da fertilidade dos solos (Beck \& Klamt, 1988). A partir desta década, os exauridos solos originalmente sob floresta foram também recuperados evoltaram a ser intensamentecultivados.

O uso agrícola desses Latossolos provocou, em muitos casos, redução no teor de matéria orgânica, enquanto com a calagem houve aumento no teor de Ca e Mg trocáveis e mi gração destes cátions no solo, com elevação do pH e diminuição no teor de Al trocável (Drescher et al., 1995). Com a adubação fosfatada ocorreu acúmulo de $\mathrm{P}$ disponível próximo à superfície do solo e, para o K disponível, verificouseincremento ou diminuição, sem, contudo, observarse migração no perfil do solo (Drescher et al., 1995). O dedínio na fertilidade do sol o sob uso agrícola em relação ao solo original, quando não se utilizam corretivos e fertilizantes e manejo adequado, é amplamente descrito na literatura (Sanchez et al., 1983; Bowman et al., 1990; Cerri et al., 1991; Correa \& Reichardt, 1995; Silva \& Ribeiro, 1995; Cravo \& Smyth, 1997; Tognon et al., 1997; ValeJ únior et al., 1998).

NoRio Grande do Sul, a partir da década de1970, com a expansão da cultura da soja, intensificaramse as práticas de cultivo em todo o Planal to Médio, com acentuada utilização de cal cário, fertilizantes, pesticidas e mecanização, além de sistemas de manejo de solo com revolvimento, que favorecem o processo de degradação (Wünsche et al., 1980). Entretanto, a partir da década de 1990, expandiuse o sistema plantio direto em toda a região, com marcante redução no processo erosivo.

É importante destacar a influência do tempo de uso agrícola sobre as características dos horizontes superficiais e subsuperficiais do solo. O objetivo deste trabalho foi determinar a influência do tempo de uso agrícola sobre as propriedades químicas de dois perfis de Latossolos Vermelhos, sendo um de textura média e outro de textura argilosa.

\section{MATERIAL E MÉTODOS}

As áreas de estudo localizam-se no município de Fortaleza dos Valos (RS), região fisiográfica do Planalto Médio. Os limites geográficos representados pelas suas coordenadas UTM são: limite lestee oeste 290.000-260.000; limite norte e sul 6.820.0006.790.000. O clima regional é subtropical úmido, 
tipo Cfa, com precipitação total anual de 1.727 mm, sendo janeiro o mês mais quente, com máxima normal de $30^{\circ} \mathrm{C}$, ejul ho o mês mais frio, com mínima normal de $8,6^{\circ} \mathrm{C}$. A altitude varia de 310 a $440 \mathrm{~m}$. Os declives entre 0 e $8 \%$ são predominantes, ocorrendo, eventualmente, encostas com $18 \%$ ou mais. As formas de relevo são homogêneas, formadas por col inas regionalmente conhecidas como coxilhas (Coelho, 1999)

Perfis de Latossolos Vermel hos em áreas sob vegetação natural ou sob uso agrícola há vários anos foram coletados nos períodos de janeiro e fevereiro/ 1997 eagosto/1997, em situações detopo de coxilha. As áreas foram sel ecionadas por meio de fotografias aéreas, imagens de satélite e entrevistas com produtores rurais. As classes de solos amostradas foram: Latossolo Vermelho distrófico típico (LVd) textura argilosa (unidade de mapeamento Passo Fundo) e Latossol o Vermel ho distrófico típico (LVd) textura média (unidade de mapeamento Cruz Alta), cuja vegetação original é floresta subtropical subcaducifólia e campo natural, respectivamente.

$\mathrm{N}$ as áreas atualmente sob uso agrícola, foi utilizado, por muitos anos, o preparo convencional do solo com arado, grade e escarificador e, mais recentemente, foi adotado o sistema plantio direto. No momento da coleta das amostras de solo, a maioria dos perfis sob uso agrícola encontrava-se no sistema plantio direto. Os tempos de uso do solo sob plantio direto dos perfis do LVd textura argilosa variaram de 1 a 8 anos e do LVd textura média variaram de 2 a 6 anos. Nas áreas amostradas, predominava o cultivo de soja e milho no verão, enquanto, no inverno, partes das áreas eram cultivadas com aveia e trigo ou permaneciam em pousio. A utilização de fertilizantes minerais e calcário foi generalizada, mas em quantidades inferiores às recomendadas para os estados do Rio Grande do Sul eSanta Catarina (CFSRS/SC, 1995).

Foram efetuadas amostragens de solo em três perfis por classe de tempo de uso no LVd textura argilosa: tempo zero (T0) = mata; tempo um (T1) = incorporados ao uso entre 1979-1989 (8-18 anos de uso); tempo dois (T2) =entre 1964-1979 (18-33 anos de uso); tempo três (T3)= incorporados anteriormente a 1964 (>33 anos de uso). No LVd textura média, amostrou-se o sol o em dois perfis por classe de tempo de uso: T0 = campo nativo; T1 = incorporados ao uso entre 1975-1989 (8-22 anos de uso); T2 =entre 1964-1975 (22-33 anos de uso), T3 = anteriormente a 1964 (>33 anos de uso). Em cada perfil, col etaram-se amostras de sol o nos horizontes $\mathrm{A} 1 / \mathrm{Ap}, \mathrm{AB}, \mathrm{BA}$ e Bw com abertura de trincheira $(0,50 \times 0,50 \times 0,50 \mathrm{~m})$ e, a partir de $0,50 \mathrm{~m}$, com trado, até uma profundidade mínima de $1,0 \mathrm{~m}$. O período de tempo de incorporação dos solos ao uso agrícol a foi determinado pela análise de fotografias aéreas de 1964 e 1975 e de imagens de satélite de 1979 a 1989. No caso de dúvidas, os agricultores foram entrevistados.
Nas amostras de solo, foram determinados $\mathrm{pH}$ em água, os teores de matéria orgânica, $\mathrm{Al}, \mathrm{Ca}$ e Mg trocáveis e P e K disponíveis (Tedesco et al., 1995). Os teores de fósforo e potássio totais foram determinados por ataque sulfúrico com $\mathrm{H}_{2} \mathrm{SO}_{4}$ 1:1. Optou-se pela extração com $\mathrm{H}_{2} \mathrm{SO}_{4}$ para o K total pela maior simplicidade do método em relação ao método do HF. Além disso, foram feitos testes com seis amostras, quando ficou demonstrado que a extração com $\mathrm{H}_{2} \mathrm{SO}_{4}$ 1:1 representou de 75 a $85 \%$ do $\mathrm{K}$ total extraído com HF (EMBRAPA, 1997a). $\mathrm{H}+\mathrm{Al}$ foi determinado com solução de acetato de $\mathrm{Ca} 0,5 \mathrm{~mol} \mathrm{~L}^{-1}$ a pH 7,0 e titulado com $\mathrm{NaOH}$ $0,0606 \mathrm{~mol} \mathrm{~L}^{-1}$, conforme EMBRAPA (1997a). Calculou-se a saturação por Al (m) e por bases (V), sendo a CTC obtida a partir da soma de bases e $\mathrm{H}+\mathrm{A}$ ). Os teores médios de argila no horizonte $\mathrm{A} 1 /$ Ap foram de 338 e $198 \mathrm{~g} \mathrm{~kg}^{-1}$, no LE textura argil osa e LE textura média, respectivamente (Quadro 1).

Por se tratar de um levantamento de campo, optou-se pela realização de equações de regressão, para estudar estatisticamente as variações dos atributos quími cos de sol o de acordo com otempo de uso agrícola, dentro de cada horizonte, para cada solo, e de correlações, para verificar a relação entre alguns atributos do solo. O número de dados utilizados (n) para cada variável para o LVd textura argilosa foi $n=12$. Entretanto, para o LVd textura média, utilizou-se $n=8$. A escol ha das equações de regressão ajustadas foi baseada no critério de nível de significância ( $P<5 \%$ ) e maior coeficiente de determinação, enquanto a das correlações baseouse nos níveis de significância que foram variáveis. O estabel ecimento das equações de regressão foi feito por meio do aplicativo estatístico SAEG (Ribeiro J unior, 2001), enquanto os coeficientes de correlação foram avaliados pelo aplicativo estatístico SOC (EMBRAPA, 1997C).

\section{RESULTADOS E DISCUSSÃO}

\section{Tempo de uso agrícola e alterações nos teores de matéria orgânica}

No solo LVd textura argilosa, constatou-se declínio no teor de matéria orgânica (MO) com o tempo de uso agrícola, principal mente no horizonte superficial (Figura 1a). Originalmente (T0), o solo apresentava 3,0 dag kg-1 de MO no horizonte superficial, mas, nos perfis com mais de 33 anos de uso agrícola (T3), o teor foi reduzido para 2,3 dag $\mathrm{kg}^{-1}$. A redução dos teores de matéria orgânica no horizonte superficial do LVd textura argilosa é comprovada estatisticamente por meio da equação de regressão: $\hat{y}=2,93-0,02 x$, em que $y=M O\left(\right.$ dag kg$\left.^{-1}\right)$ e $x=$ tempo (ano), $R^{2}=0,30$, com nível de significância $\alpha=0,05$. Com o uso agrícola tende-se à redução no teor de MO pelo aumento na taxa de 
Quadro 1. Teores de argila, matéria orgânica, cálcio e alumínio em perfis (P) que representam pontos amostrados em áreas com tempos (T) de uso agrícola

\begin{tabular}{|c|c|c|c|c|c|c|c|c|c|c|c|c|c|c|c|c|}
\hline \multirow{3}{*}{ Perfil } & \multicolumn{16}{|c|}{ Horizonte } \\
\hline & \multicolumn{4}{|c|}{ Al/Ap } & \multicolumn{4}{|c|}{ AB } & \multicolumn{4}{|c|}{ BA } & \multicolumn{4}{|c|}{ BW } \\
\hline & Arg & MO & $\mathrm{Ca}^{2+}$ & $\mathbf{A l}^{3+}$ & Arg & MO & $\mathrm{Ca}^{2+}$ & $\mathrm{Al}^{3+}$ & Arg & MO & $\mathrm{Ca}^{2+}$ & $\mathbf{A l}^{3+}$ & Arg & MO & $\mathrm{Ca}^{2+}$ & $\mathrm{Al}^{3+}$ \\
\hline & \multicolumn{2}{|c|}{$-\mathrm{g} \mathrm{kg}^{-1}-$} & \multicolumn{2}{|c|}{$-\mathrm{Cmol}_{\mathrm{c}} \mathrm{dm}^{-3}{ }_{-}$} & \multicolumn{2}{|c|}{$-\mathrm{gkg}^{-1}-$} & \multicolumn{2}{|c|}{$-\mathrm{cmol}_{\mathrm{c}} \mathrm{dm}^{-3}{ }^{-}$} & \multicolumn{2}{|c|}{$\begin{array}{l}-\mathrm{g} \mathrm{kg}^{-1}- \\
\text { a argilosa }\end{array}$} & \multicolumn{2}{|c|}{$-\mathrm{cmol}_{c} \mathrm{dm}^{-3}{ }_{-}$} & \multicolumn{2}{|c|}{$-\mathrm{g} \mathrm{kg}^{-1}-$} & \multicolumn{2}{|c|}{$-\mathrm{cmol}_{\mathrm{c}} \mathrm{dm}^{-3}-$} \\
\hline P1-TC & 326 & 26 & 4,2 & 2,0 & 359 & 16 & 1,3 & 4,0 & 461 & 9 & 0,8 & 4,0 & 534 & 5 & 0,6 & 4,0 \\
\hline P2-TO & 284 & 29 & 1,3 & 3,2 & & 17 & 06 & & 335 & 11 & & 4,0 & 400 & 5 & ( & 4,5 \\
\hline P3-TC & 407 & 35 & 7,2 & 0,1 & 412 & 25 & 2,2 & 2,7 & 415 & 21 & 1,4 & 3,1 & 516 & 13 & 1,7 & 2,4 \\
\hline P1-T1 & 341 & 23 & 9,0 & 0,0 & 397 & 13 & 5,8 & 0,2 & 470 & 9 & 1,6 & 3,4 & 534 & 4 & 1,3 & 3,6 \\
\hline $\mathrm{P} 2-\mathrm{T}]$ & 294 & 26 & 3,1 & 2,0 & 326 & 14 & 0,9 & 3,9 & 381 & 10 & 0,9 & 3,7 & 375 & 15 & 0,6 & 3,4 \\
\hline P3-T & 35 & 30 & 8,1 & 0,0 & 409 & 11 & 5,0 & 0,2 & 476 & 9 & 3 & 1,1 & 580 & 5 & 1,6 & 2,6 \\
\hline P1-T2 & 37 & 14 & 4,0 & 1, & 465 & 05 & 2,2 & 2,5 & 586 & 4 & 2,4 & 2 & 615 & 4 & 1,8 & 2,5 \\
\hline P2-T2 & 365 & 34 & 9,2 & 0,0 & 357 & 21 & 4,6 & 0,4 & 421 & 17 & 2,5 & 2,0 & 538 & 10 & 1,7 & 2,5 \\
\hline P3-T2 & 397 & 24 & 6,4 & 0,0 & 472 & 14 & 3,1 & 1,7 & 542 & 12 & 1,6 & 3,0 & 563 & 5 & 1,3 & 3,1 \\
\hline \multicolumn{17}{|c|}{ LVd textura média } \\
\hline P1-T & 33 & 21 & $5,($ & 0 , & 5 & 10 & 3,1 & 1,3 & 473 & 7 & 3,1 & 1,5 & 5 & 4 & 9 & 1,2 \\
\hline P2-T & 33 & 24 & 5,6 & 0, & 40 & 21 & 30 & & 43 & 14 & 2 & & 56 & 5 & 1 & 2,1 \\
\hline P3-T & 34 & 2 & 5, & 0 , & 408 & 20 & 2 , & & & 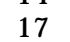 & & & & 7 & & \\
\hline P1-T & 211 & 20 & 1,2 & 1, & 240 & 1,6 & 0,9 & 2,4 & 304 & 12 & 1,2 & 2, & 35 & 9 & 1,3 & 2,4 \\
\hline$P 2-T$ & 16 & 17 & & 1, & $1 \varepsilon$ & & & & 26 & & & & 30 & 7 & 0,3 & 2,3 \\
\hline P1-T1 & 153 & 16 & 1,9 & 0,3 & 156 & 1,2 & 0,4 & 1,7 & 210 & 10 & 0,3 & 2,3 & 247 & 7 & 0,3 & 2,3 \\
\hline P2-T & 245 & 25 & 3,4 & 0, & 297 & 2,0 & 1,3 & & 383 & 15 & 1, & & 491 & 8 & 1,4 & 1,5 \\
\hline $\mathrm{P} 1-\mathrm{T}$ & 166 & 15 & 1,6 & 1,0 & 230 & 1,3 & 1,1 & 1,9 & 300 & 8 & 0,9 & 2,2 & 330 & 5 & 0,9 & 1,8 \\
\hline P2-T & 153 & 16 & 1,0 & 1,5 & 201 & 1,2 & 0,9 & 2,0 & 268 & 10 & 0,9 & 2, & 304 & 6 & 0,9 & 1,7 \\
\hline P1-T3 & 298 & 21 & 4,7 & 0,0 & 373 & 1,7 & 1,9 & 2 & 459 & 11 & 2,1 & 2,1 & 492 & 8 & 2,4 & 1,4 \\
\hline P2-T3 & 140 & 18 & 0,7 & 1,3 & 215 & 1,3 & 0,5 & 1,9 & 250 & 9 & 0,6 & 1,6 & 272 & 4 & 0,5 & 1,7 \\
\hline
\end{tabular}

decomposição, especialmente quando o preparo do solo é feito com revolvimento, causando um balanço negativo entre adição e perda de carbono no solo (Bayer, 1996). Como as áreas estudadas encontramse atualmente sob sistema plantio direto, essa tendência de redução no teor de MO poderá ser revertida.

No LVd textura média, não se verificou uma variação esperada noteor de matéria orgânica entre os perfis (F igura 1 b). A correlação positiva entre MO eargila no horizonte superficial $r=0,7536(P=0,031)$ evidenciou a proteção física da MO proporcionada pela argila. Além disso, como os perfis sob uso agrícola estão sendo cultivados no sistema plantio direto por um período que varia de dois a seis anos e como original mente esse sol o já apresentava baixo teor de MO, devido, dentre outros fatores, à baixa produção de matéria vegetal em campo nativo, é compreensível que os perfis sob uso agrícola apresentassem teores de MO semelhantes ou superiores aos dos perfis sob vegetação nativa.

Tognon et al. (1997) também constataram menor redução no teor de MO para o solo originalmente sob cerrado do que para solo origi nal mente sob mata, pela incorporação dos solos ao uso agrícola. Isso confirma que, em ambientes com mai ores produções de matéria seca, onde originalmente oteor de MO é mais el evado, a taxa de decomposição da MO pela incorporação do solo ao uso agrícola é maior.

Comparando as variações nos teores de MO nos dois sol os, admite-se que uma das justificativas para o decréscimo no teor com o uso agrícola no LVd textura argilosa seja a sua comparação com uma testemunha que era área de floresta, enquanto, no LVd textura média, a testemunha era área de campo nativo, cuja fertilidade natural é, em sua maioria, baixa, significando baixo potencial à produção de matéria seca das pastagens, justificando os baixos teores naturais de MO. N este caso, seu uso agrícola normalmentesignifica melhoria na disponibilidade de nutrientes, que, favorecendo a produção de matéria seca das culturas, aumenta a adição de carbono ao solo e, conseqüentemente, el eva o teor de MO.

\section{Tempo de uso agrícola e alterações nos teores de cálcio, magnésio e alumínio, nos valores de pH e nos índices de saturação por bases e por alumínio}

As variações nos teores de $\mathrm{Ca}^{2+} \mathrm{e} \mathrm{M} \mathrm{g}^{2+}$, conforme o tempo de uso agrícola do solo, são mostradas na 


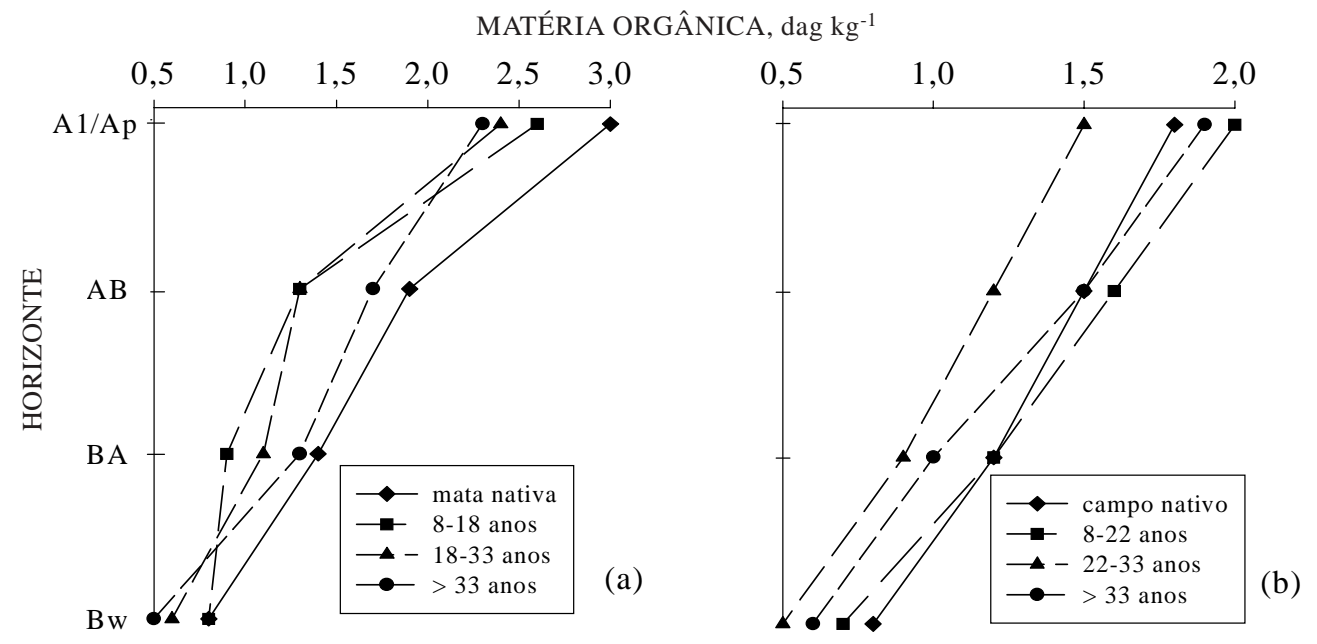

Figura 1. Efeito do tempo de uso agrícola sobre o teor de matéria orgânica do LVd textura argilosa(a) e do LVd textura média (b).

figura 2. No horizonte superficial do LVd textura argilosa, ocorreu incremento no teor de $\mathrm{Ca}^{2+}$ com o uso do solo, graças à prática da calagem, mas este incremento não foi tão acentuado, com uma tendência de declínio dos teores nos maiores tempos de uso do solo (>33 anos). Esta tendência de declínio no teor de $\mathrm{Ca}^{2+}$ nos perfis com maior tempo de uso deveu-se, provavelmente, não sóà maior exportação dos cátions pelas culturas, lixiviação e erosão, mas também à menor aplicação de calcário, já que os perfis com mais de 33 anos de uso agrícola (T3) eram os que se encontravam por mais tempo sob plantio direto (4 a 8 anos), sistema em que menores quantidades de cal cário são aplicadas.

No entanto, nos horizontes mais profundos, verificou-seincremento praticamentelinear noteor de $\mathrm{Ca}^{2+}$ com o uso agrícola do solo. No horizonte Bw, o aumento foi de 0,9 para $2,1 \mathrm{cmol}^{\mathrm{dm}^{-3} \text { nos }}$ perfis com mais de 33 anos de uso agrícola (T3) em relação aos perfis sob mata (T0). I sso mostra que ocorreu migração de $\mathrm{Ca}^{2+}$ no perfil do solo (Figura 2a). No quadro 2, estão apresentadas as equações de regressão para o $\mathrm{Ca}^{2+}$ conforme o tempo de uso agrícola.

Apesar de não se obterem equações de regressão significativas com os resultados de incremento do $\mathrm{Mg}^{2+}$ de acordo com o tempo de uso agrícola, o incremento de $\mathrm{Mg}^{2+}$ no LVd textura argilosa foi menor do que de $\mathrm{Ca}^{2+}$ (Figura $2 \mathrm{C}$ ) havendo também migração no perfil do solo. Verificam-seincrementos de $\mathrm{Ca}^{2+}{ }^{2+}$ de $\mathrm{Mg}^{2+}$ no perfil no L Vd textura média com o uso agrícola, com migração no perfil do solo (Figuras 2b e 2d).

Utilizando o histórico de manejo dosol o, percebeuse que o incremento de $\mathrm{Ca}^{2+}{\mathrm{e} \mathrm{Mg}^{2+} \text { deveu-se à }}^{2}$ aplicação de cal cário. A migração de $\mathrm{Ca}^{2+} \mathrm{e} \mathrm{Mg}^{2+}$ no perfil do solocom o uso agrícola também foi observada por Cerri et al., 1991; Silva \& Ribeiro, 1995; Tognon et al., 1997; Vale J únior et al., 1998. O Ca ${ }^{2+} \mathrm{e} \mathrm{Mg}^{2+}$ migram no perfil, provavel mente pela lixiviação com ânions acompanhantes (Mengel \& Kirkby, 1979).

Originalmente, os solos apresentavam altos teores de $\mathrm{Al}^{3+}$, tanto no sol o sob mata ( $\mathrm{LVd}$ textura argilosa) quanto no solo sob campo nativo ( $L V d$ textura média) (Figuras 2e e2f). Com o uso agrícola houve diminuição nos teores de $\mathrm{Al}^{3+}$ e el evação do pH em relação ao sol o original (T0), em razão do uso de cal cário, tal como nos resultados obtidos por Silva \& Ribeiro (1995).

Pelas regressões (Quadros 2 e 3), constata-se que, nos horizontes mais profundos, os teores de $\mathrm{Al}^{3+}$ decresceram linearmente com o tempo de uso agrícola, enquanto, no horizonte superficial, em razão da interferência direta da ação dos cultivos, as equações ajustadas foram de mai or complexidade. No quadro 2, estão apresentadas as equações de regressão dos valores de $\mathrm{pH}$ de acordo com o tempo de uso agrícola para o L Vd textura argilosa. Com a elevação do pH do solo, o Al trocável precipita na forma de hidróxido e, segundo Volkweiss (1989), em solos com pH igual ou superior a aproximadamente 5,5 , os teores de Al trocável são insignificantes, porém, à medida que o $\mathrm{pH}$ diminui, os teores aumentam sensivelmente. Essa relação entre Al trocável e pH foi constatada nos dois solos. Assim, a toxidez de alumínio às plantas foi mais severa até pH 5,0 (F oy et al., 1978).

O incrementonos teores de $\mathrm{Ca}^{2+} \mathrm{eMg}^{2+}$ ea redução no teor de $\mathrm{Al}^{3+}$ no horizonte subsuperficial dos solos, de acordo com o tempo de uso agrícola, poderão facilitar o aprofundamento do sistema radicular, por reduzir o impedimento químico ao crescimento de raízes.

Os resultados mostram que, originalmente, os solos apresentavam baixo valor de saturação por bases e al to de saturação por al umínio, sendo ambos classificados comoálicos (E MBRAPA, 1997b). O LVd 


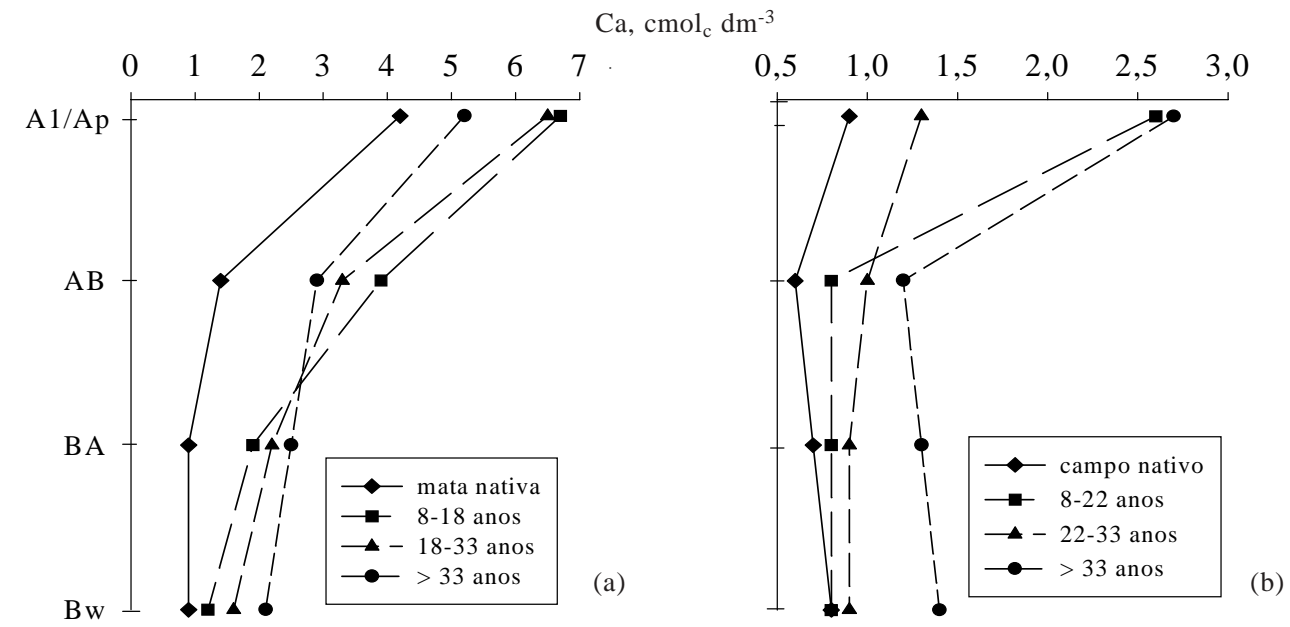

$\mathrm{Mg}, \mathrm{cmol}_{\mathrm{c}} \mathrm{dm}^{-3}$

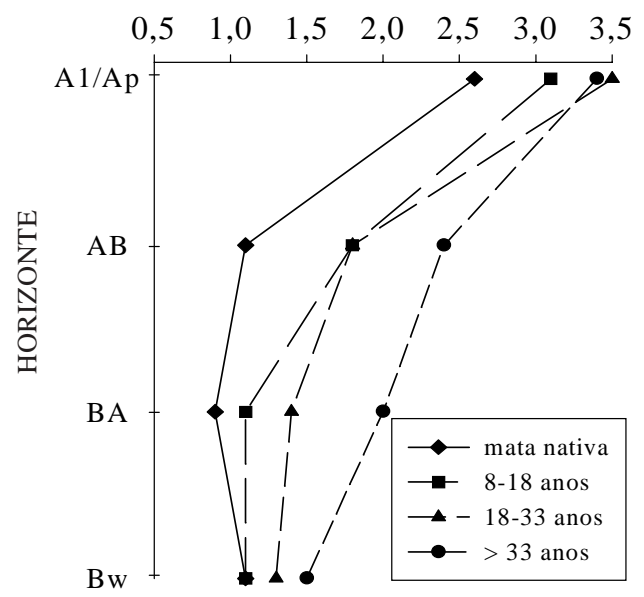

(c)

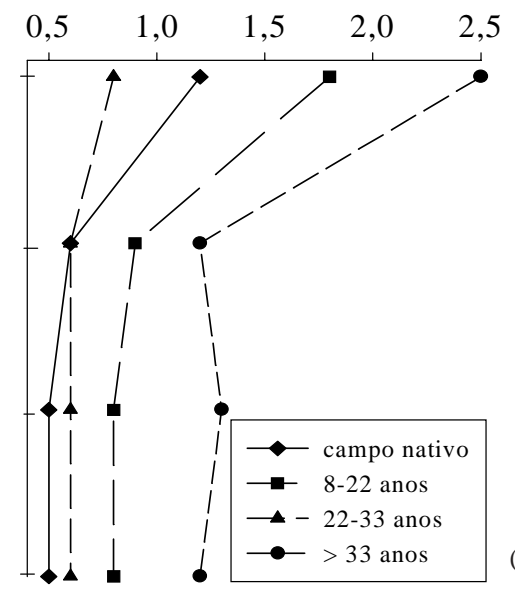

Al TROCÁVEL, $\mathrm{cmol}_{\mathrm{c}} \mathrm{dm}^{-3}$
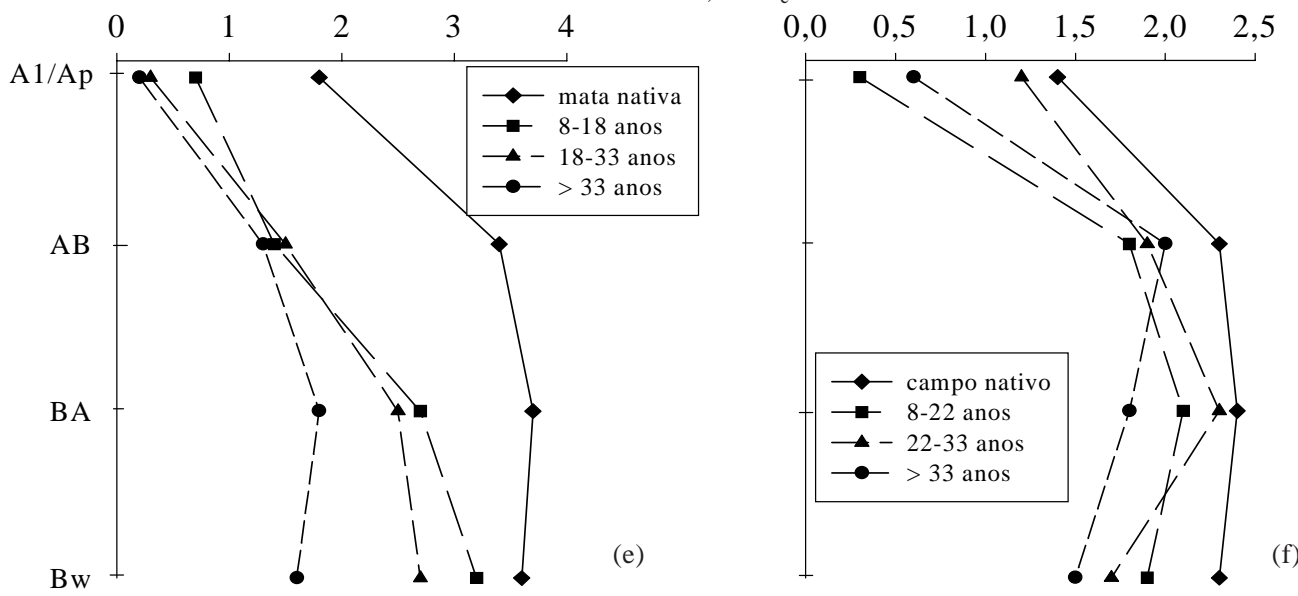

Figura 2. Efeito do tempo de uso agrícola sobre os teores de cálcio, magnésio e alumínio trocáveis do LVd textura argilosa (a, c e e) e do LVd textura média (b, d e f).

textura argilosa apresentou no horizonte BA saturação por bases de $16 \%$ e saturação por alumínio de $68 \%$, enquanto o LVd textura média apresentou no horizonte BA saturação por bases de 16 \% e saturação por alumínio de $65 \%$.
Com o uso agrícola, ocorreu aumento da saturação por bases no LVd textura argilosa e no LVd textura média, bem como conseqüente redução na saturação por alumínio. A el evação na saturação por bases de ambos os solos não foi suficiente para 
Quadro 2. Equações de regressão(1) para cálcio e alumínio trocáveis, $\mathrm{pH}$, saturação por bases (V) e saturação por alumínio $(\mathrm{m})$, considerando o tempo (ano) de uso agrícola do solo L Vd textura argilosa

\begin{tabular}{|c|c|c|}
\hline Horizonte & E quação de regressão & $\mathbf{R}^{2}$ \\
\hline \multicolumn{3}{|c|}{ Ca trocável, $\mathrm{cmol}_{c} \mathrm{dm}^{-3}$} \\
\hline A & $\hat{y}=4,28+0,23 x-0,005 x^{2}$ & 0,25 \\
\hline$A B$ & $\hat{y}=1,50+0,19 x-0,004 x^{2}$ & 0,34 \\
\hline B A & $\hat{y}=1,15+0,03 x$ & 0,45 \\
\hline B w & $\hat{y}=0,87+0,37 x$ & 0,47 \\
\hline \multicolumn{3}{|c|}{ M g trocável, $\mathrm{cmol}_{\mathrm{c}} \mathrm{dm}^{-3}$} \\
\hline A & $\hat{y}=2,77+0,0188 x$ & 0,04 \\
\hline$A B$ & $\hat{y}=1,25+0,026 x$ & 0,19 \\
\hline B A & $\hat{y}=0,86+0,024 x$ & 0,25 \\
\hline B w & $\hat{y}=1,054+0,0089 x$ & 0,33 \\
\hline \multicolumn{3}{|c|}{ Al trocável, $\mathrm{cmol}_{\mathrm{c}} \mathrm{dm}^{-3}$} \\
\hline A & $\hat{y}=1,77-0,43 \ln (x)$ & 0,36 \\
\hline$A B$ & $\hat{y}=3,31-0,59 \ln (x)$ & 0,41 \\
\hline B A & $\hat{y}=3,50-0,04 x$ & 0,47 \\
\hline B w & $\hat{y}=3,71-0,05 x$ & 0,62 \\
\hline \multicolumn{3}{|c|}{$\mathrm{pH}$} \\
\hline A & $\hat{y}=4,42+0,08 x-0,002 x^{2}$ & 0,36 \\
\hline$A B$ & $\hat{y}=4,23+0,16 \ln (x)$ & 0,25 \\
\hline B A & $\hat{y}=4,14+0,13 \ln (x)$ & 0,27 \\
\hline$B \mathrm{w}$ & $\hat{y}=4,15+0,01 x$ & 0,47 \\
\hline \multicolumn{3}{|c|}{$v, \%$} \\
\hline B A & $\hat{y}=18,57+0,57 x$ & 0,40 \\
\hline B w & $\hat{y}=18,06+0,47 x$ & 0,37 \\
\hline \multicolumn{3}{|c|}{$m, \%$} \\
\hline B A & $\hat{y}=60,77-0,72 x$ & 0,42 \\
\hline B w & $\hat{y}=68,20-0,82 x$ & 0,44 \\
\hline
\end{tabular}

(1) $\mathrm{P}<0,05$.

classificá-los como eutróficos, mas a diminuição na saturação por alumínio foi suficiente para os perfis com maior tempo de uso agrícola perderem o caráter álico e serem classificados como distróficos. O horizonte BA do LVd textura argilosa, nos perfis com mais de 33 anos de uso agrícola (T3), apresentou saturação por bases de $43 \%$ e saturação por alumínio de $28 \%$, enquanto o horizonte BA do LVd textura média nos perfis com mais de 33 anos de uso agrícola (T3) apresentou saturação por bases de 32 \% esaturação por al umínio de $42 \%$. As equações deregressão comprovam estatisticamente a el evação da saturação por bases e a diminuição da saturação por alumínio no LVd textura argilosa (Quadro 2) e LVd textura média (Quadro 3).

\section{Tempo de uso agrícola e alterações nos teores de fósforo e potássio}

Sendo o $\mathrm{P}$ pouco móvel no solo, eram esperadas melhorias no teor de $\mathrm{P}$ disponível nos horizontes superficiais com os consecutivos cultivos e fertilizações fosfatadas, desde que os fenômenos erosivos estivessem sob relativo controle. Assim, com o uso agrícola e conseqüentes adubações fosfatadas, verificou-se acúmulo de $\mathrm{P}$ disponível no horizonte superficial no LVd textura argilosa e no LVd textura média (Figuras 3a e 3b).

Comparando os perfis sob vegetação natural (T0) com os de maior tempo de uso (T3), o aumento em P disponível no horizonte superficial foi de 4,6 para $15,5 \mathrm{mg} \mathrm{dm}^{-3}$, no LVd textura argilosa, e de 2,0 para $5,6 \mathrm{mg} \mathrm{dm}^{-3}$, no LVd textura média. Os aumentos ocorridos no horizonte superficial no LVd textura argilosa foram confirmados estatisticamente pela equação de regressão: $\hat{y}=4,67+0,24 x$, em que $y=$ $\mathrm{P}$ e $\mathrm{x}=$ tempo (ano), $\mathrm{R}^{2}=0,40$, com significância $\alpha=0,05$.

O uso agrícola pode ocasionar incrementos nos teores de P disponível do solo (Patella, 1980; Cerri et al., 1991; Silva \& Ribeiro, 1995; e Tognon et al., 1997), mas é importante considerar a ressalva de Rheinheimer et al. (1999) de que a interferência humana no ciclo natural do $P$ é degradativa.

Os teores deP total mostraram-se mais el evados no sol o de textura argil osa do que no sol o de textura média, evidenciando a relação entre $\mathrm{P}$ e textura do sol o (Quadro 4). As variaçỗes ocorridas com o teor de $\mathrm{P}$ total, entre os perfis no LVd textura média, foram muito influenciadas pelos teores de argila e de matéria orgânica, apresentando coeficientes de correlação entre teor de $\mathrm{P}$ total e teor de argila de $\mathrm{r}$ $=0,7039(P=0,051)$, para o horizonte $A ; r=0,8112$ $(P=0,015)$, para ohorizonte $A B ; r=0,9116(P=0,002)$, para o horizonte $\mathrm{BA}$, er $=0,8578(\mathrm{P}=0,006)$, para o horizonte Bw. Por sua vez, os resultados mostraram coeficientes de correl ação entre teor de P total eteor

Quadro 3. Equações de regressão(1) para alumínio trocável, saturação por bases (V) e saturação por alumínio (m), considerando o tempo (ano) de uso agrícola do solo LVd textura média

\begin{tabular}{|c|c|c|}
\hline Horizonte & Equação de regressão & $\mathbf{R}^{2}$ \\
\hline \multicolumn{3}{|c|}{ Al trocável } \\
\hline$A$ & $\hat{y}=1,47-0,30 x+0,02 x^{2}-0,0003 x^{3}$ & 0,57 \\
\hline$A B$ & $\hat{y}=2,24-0,04 x+0,001 x^{2}$ & 0,59 \\
\hline BA & $\hat{y}=2,41-0,01 x$ & 0,39 \\
\hline $\mathrm{Bw}$ & $\hat{y}=2,34-0,02 x$ & 0,76 \\
\hline \multicolumn{3}{|c|}{$\vee \%$} \\
\hline$A B$ & $\hat{y}=16,64+0,32 x$ & 0,53 \\
\hline \multicolumn{3}{|c|}{$\mathrm{m} \%$} \\
\hline$A B$ & $\hat{y}=64,15-0,53 x$ & 0,44 \\
\hline
\end{tabular}

(1) $\mathrm{P}<0,05$. 
de matéria orgânica der $=0,7800(P=0,022)$, para o horizonte $A B$, e de $r=0,7963(P=0,018)$, para o horizonte Bw.

Nos perfis do LVd textura argilosa, as variações ocorridas no teor deP total foram influenciadas pel o teor de argila, com coeficientes de correlação entre teor de $P$ total eteor deargila der $=0,6014(P=0,039)$, para o horizonte $A ; r=0,8516(P=0,000)$, para o horizonte $A B$, er $=0,8179(P=0,001)$, para ohorizonte Bw. Entretanto, comparando os resultados de $P$ total dos perfis em T0 (sol o sob vegetação nativa) com os perfis de sol o sob uso agrícol a T1, T2 eT3, ou seja, sol os com até mais de 33 anos de uso agrícola, foram observados teores mais elevados nos perfis sob uso agrícola, com equação de regressão ajustada para o horizonte superficial do LVd textura argi losa, de acordo com o tempo de uso agrícola: $\hat{y}=495,61$ $+18,69 x-0,30 x^{2}$, em que $y=P$ total e $x=$ tempo (anos), $R^{2}=0,59$, nível de significância $\alpha=0,05$. Observou-se influência do teor de argila e matéria orgânica no teor de $\mathrm{P}$ deste solo, mas o manejo do solo ao longo do tempo de uso com adubações fosfatadas, principal mente no horizonte superficial, teve efeito marcante na concentração deP neste solo.

As variações nos teores de $\mathrm{K}$ disponível foram mais expressivas no horizonte superficial de ambos os sol os (Figuras 3c e 3d). No horizonte superficial do LVd textura argilosa, observou-se decréscimo no teor de $\mathrm{K}$ disponível com o aumento no tempo de uso agrícola do solo e isso é quantificado na equação de regressão: $\hat{y}=101,97+5,53 x-0,14 x^{2}$, e que $y=$ $K$ trocável ex $=$ tempo (anos), $R^{2}=0,45$, com nível de significância $\alpha=0,05$.

Entretanto, em ambos os solos e no horizonte superficial, os teores de K disponível variaram de médios a altos (CFSRS/SC, 1995), demonstrando que o uso agrícola pode também proporcionar acréscimos noteor deK disponível no solo. Isso está evidenciado nolevantamento da situação da fertilidade dos sol os no estado do RS, com base nos valores de 168.200 análises de sol os realizadas de 1997 a 1999, em que $58,7 \%$ das amostras apresentavam teor de

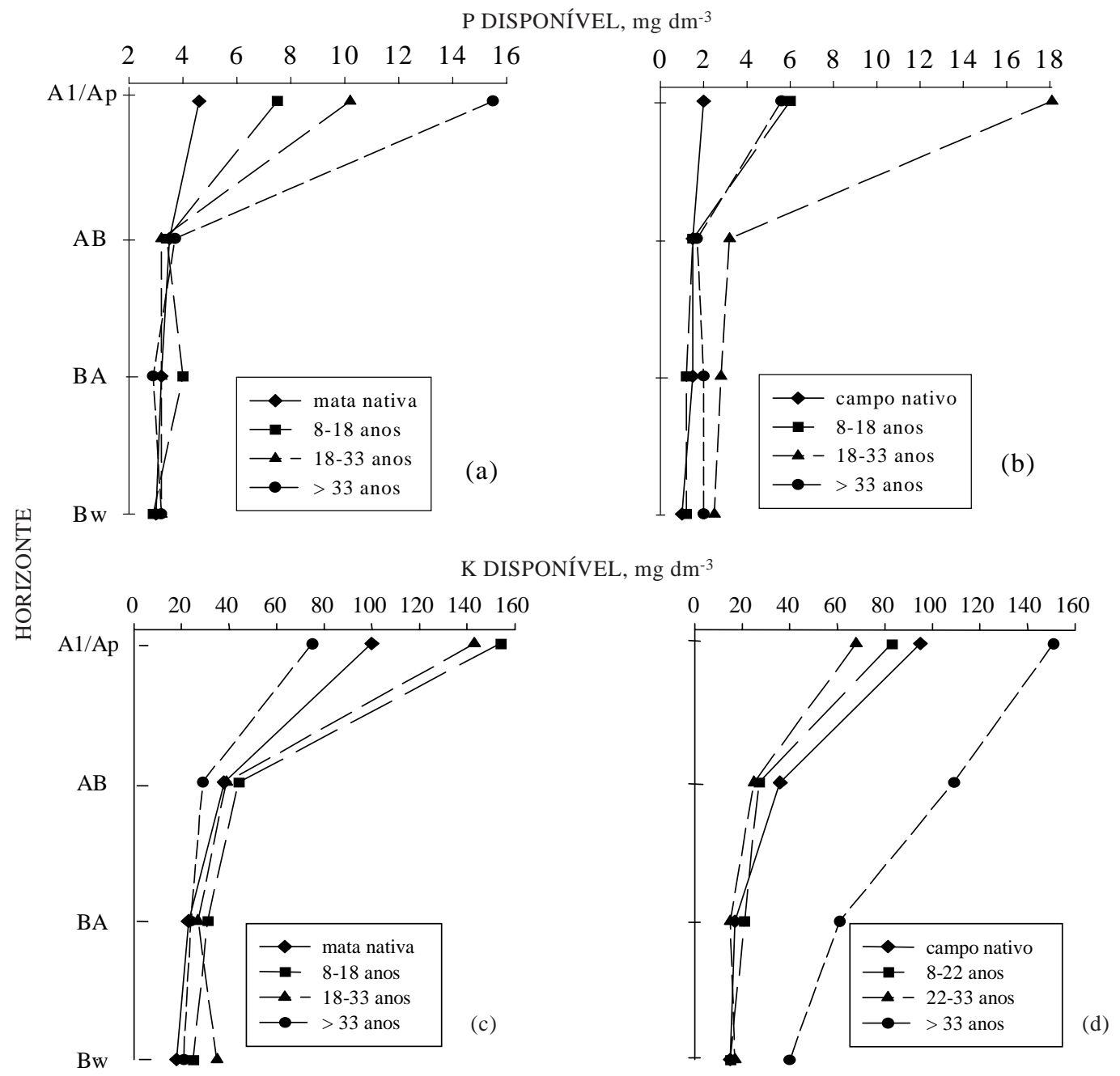

Figura 3. E feito do tempo de uso agrícola sobre os teores de potássio e fósforo disponíveis do LVd textura argilosa (a e c) e do LVd textura média (b e d). 
K disponível acima do nível crítico, que é de $80 \mathrm{mg} \mathrm{dm}^{-3}$ (Rheinheimer et al. 2001). Entretanto, pode-seconsiderar o val or de $73,1 \%$, pois a CFSRS/ SC baixou o nível crítico de K disponível para $60 \mathrm{mg} \mathrm{dm}^{-3}$ (CFSRS/SC, 2001).

Observaram-se teores mais elevados de $\mathrm{K}$ total no sol o detextura argilosa do que no sol o de textura média, inclusive com incremento do teor em profundidade no LVd textura média, acompanhando, aproximadamente, o aumento do teor de argila no perfil desse solo (Quadro 4). É provável que as menores variações em profundidadeno LVd textura argilosa possam ser justificadas pelos altos teores de $\mathrm{K}$ total existente naturalmente neste solo. Meurer et al. (1996), estudando as formas de ocorrência de $\mathrm{K}$ e a mineralogia de um Latossolo Vermelho distroférrico típico (unidade de mapeamento Santo Ângelo), constataram que 76 \% do K total estava localizado na fração argila.

As variações ocorridas com o teor de K total, entre os perfis do LVd textura média, foram bastante influenciadas pelos teores de argila e de matéria orgânica. Isso é confirmado pelos coeficientes de correlação entre teor de $\mathrm{K}$ total eteor de argila de $\mathrm{r}=$ $0,9414(P=0,000)$, para o horizonte $A ; r=0,9396$ $(P=0,001)$, para o horizonte $A B ; r=0,9382(P=$ $0,001)$, para ohorizonte $B A$, er $=0,9259(P=0,001)$, para o horizonte Bw, e pelos coeficientes de correlação entre teor de $\mathrm{K}$ total e teor de matéria orgânica $r=0,6818(P=0,063)$, para o horizonte $A$, e $r=0,6403(P=0,087)$, para o horizonte $A B$, que confirmam esta assertiva. As variações ocorridas com o teor de $\mathrm{K}$ total nos perfis do LVd textura argilosa foram influenciadas pela variação no teor de argila entreamostras, mostrado pel os coeficientes de correlação entre teor de $\mathrm{K}$ total e teor de argila de $r=0,7846(P=0,003)$, para o horizonte $A$, e $r=$ $0,5247(P=0,080)$, para o horizonte Bw. Entretanto, verificou-se tendência de aumento nos teores de $\mathrm{K}$ total com o tempo de uso agrícola nos horizontes mais profundos, em ambos os solos (Quadro 4).

\section{CONCLUSÕES}

1. A diminuição no teor de matéria orgânica do solo com o tempo de uso agrícola foi perceptível, quando originalmente os solos eram de florestas, enquanto, em solos de campo nativo, o uso agrícola promoveu acréscimo no teor de matéria orgânica.

2. Nutrientes como Ca e Mg trocáveis tiveram incremento no solo com o tempo de uso agrícola, ao contrário do Al trocável que diminuiu seu teor e saturação em profundidade.

3. Com o tempo de uso agrícola, os incrementos de $P$ total foram evidentes nos horizontes superficiais, enquanto os incrementos de K total também ocorreram em profundidade.

\section{LITERATURA CITADA}

BAYER, C. Dinâmica da matéria orgânica em sistemas de manejo de solos. Porto Alegre, Universidade Federal do Rio Grande do Sul, 1996. 240p. (Tese de Doutorado)

\section{Quadro 4. Fósforo e potássio totais do solo LVd textura argi losa e LVd textura média em diversos perfis sob vegetação nativa e tempos de uso agrícola}

\begin{tabular}{|c|c|c|c|c|c|c|c|c|}
\hline Horizonte & TO & T1 & $\mathbf{T 2}$ & T3 & TO & T1 & T2 & T3 \\
\hline & \multicolumn{4}{|c|}{ P-total - LVd textura argilosa(1) } & \multicolumn{4}{|c|}{ P-total - LVd textura média(2) } \\
\hline A1/Ap & 521 & 616 & 832 & 727 & 249 & 389 & 363 & 373 \\
\hline$A B$ & 475 & 557 & 703 & 591 & 249 & 303 & 279 & 294 \\
\hline BA & 476 & 535 & 684 & 544 & 264 & 309 & 279 & 325 \\
\hline \multirow[t]{2}{*}{ Bw } & 470 & 512 & 671 & 544 & 264 & 309 & 264 & 281 \\
\hline & \multicolumn{4}{|c|}{ K-total - LVd textura argilosa(1) } & \multicolumn{4}{|c|}{ K-total - LVd textura média(2) } \\
\hline Al/Ap & 1.347 & 1.314 & 1.398 & 1.111 & 781 & 883 & 756 & 1.136 \\
\hline$A B$ & 1.212 & 1.161 & 1.128 & 1.145 & 807 & 857 & 807 & 1.187 \\
\hline $\mathrm{BA}$ & 1.229 & 1.179 & 1.246 & 1.263 & 883 & 933 & 1.009 & 1.288 \\
\hline Bw & 1.381 & 1.364 & 1.499 & 1.601 & 1.060 & 1.136 & 1.136 & 1.364 \\
\hline
\end{tabular}

(1) T0 = mata nativa; T1 = 8-18 anos de uso; T2 = 18-33 anos de uso; T3 = > 33 anos de uso. ${ }^{(2)}$ T0 = campo nativo; T1 = 8-22 anos de uso; T2 =22-33 anos de uso; T3 =>33 anos de uso. 
BECK, F.L. \& KLAMT, E. Organização do conteúdo do ensino de solos e sua relação com a sociedade. In: MONIZ, A.C., ed. A responsabilidade social da ciência do solo. Campinas, Sociedade Brasileira de Ciência do Solo, 1988. p.169-181.

BOWMAN, R.A.; REEDER, J .D. \& LOBER, R.W. Changes in soil properties in a central plains rangeland soil after 3, 20 and 60 years of cultivation. Soil Sci., 150:851-857, 1990.

BRASI L. Ministério da Agricultura, Departamento Nacional de Pesquisa Agropecuária, Divisão de Pesquisa Pedológica. Levantamento de reconhecimento dos sol os do Rio Grande do Sul. Recife, 1973, 431p. (Boletim Técnico, 30)

CERRI, C.C.; FELLER, C. \& CHAUVEL, A. Evolução das principais propriedades de um latossolo vermel ho escuro após desmatamento e cultivo por doze e cinqüenta anos com cana-de-açúcar. Cah. Orston, Sér. Pédol., 26:37-50, 1991.

COELHO, O.W. Modelamento da degradação de Latossolos na região de Fortaleza dos Valos, RS - Uma aplicação SIG/ sensoriamento remoto. Porto Alegre, U niversidade Federal do Rio Grande do Sul, 1999. 165p. (Tese de Doutorado)

COMISSÃO DE FERTILIDADE DO SOLO-CFSRS/SC. Recomendações de adubação e de calagem para os Estados do Rio Grande do Sul e Santa Catarina. 3.ed. Passo F undo, Sociedade Brasileira de Ciência do Solo - Núcleo Regional Sul. E mpresa Brasileira de Pesquisa Agropecuária/CNPT, 1995. 223p.

COMISSÃO DE FERTILIDADE DO SOLO-CFSRS/SC. Recomendações de adubação e de calagem para os Estados do Rio Grande do Sul e Santa Catarina. 3.ed. Passo F undo, Sociedade Brasileira de Ciência do Solo - Núcleo Regional Sul. Empresa Brasileira de Pesquisa Agropecuária/CNPT, 2001. 4p. (Circular Técnica, 2)

CORREA, J.C. \& REICHARDT, K. Efeito do tempo de uso das pastagens sobre as propriedades de um Latossol o Amarelo da Amazônia central. Pesq. Agropec. Bras., 30:107-114, 1995.

CRAVO, M.S. \& SMYTH, T.J . Manejo sustentado da fertilidade de um Latossolo da Amazônia Central sob cultivos sucessivos. R. Bras. Ci. Solo, 21:607-616, 1997.

DRESCHER, M.; BISSANI, C.A.; GIASSON, E.;TEDESCO, M.J . \& GIANELLO, C. Avaliação da fertilidade dos solos do estado do Rio Grande do Sul e necessidades de adubos e corretivos. Porto Alegre, Universidade Federal do Rio Grande do Sul, 1995. 24p. (Boletim Técnico de Solos, 7)

EMPRESA BRASILEIRA DE PESQUISA AGROPECUÁRIA EMBRAPA. Manual de métodos de análise de solo. 2.ed. Rio de J aneiro, Centro Nacional de Pesquisa de Solos, 1997a. 212p.

EMPRESA BRASILEIRA DE PESQUISA AGROPECUÁRIA EMBRAPA. Sistema brasileiro de classificação de solos: $4^{a}$ aproximação. Rio de J aneiro, Centro Nacional de Pesquisa de Solos, 1997b. 169p.

EMPRESA BRASILEIRA DE PESQUISA AGROPECUÁRIA EMBRAPA. Ambiente de software NTIA, versão 4.2.2: manual do usuário - ferramental estatístico. Campinas, Centro Nacional de Pesquisa Tecnológica em I nformática para a Agricultura, 1997c. 258p.
FOY, C.D.; CHANEY, R.L. \& WHITE, M.C. The physiology of metal toxicity in plants. Ann. Rev. Plant Physiol., 29:511566, 1978.

MENGEL, K. \& KIRKBY, E.A. Principles of plant nutrition.2.ed. Switzerland, Potash, 1979. 593p.

MEURER, E.J .; KAMPF, N.\& ANGHINONI, I. Fontes potenciais de potássio em alguns solos do Rio Grande do Sul. R. Bras. Ci. Solo, 20:41-47, 1996.

PATELLA, J .F. Influência de quinze anos de adubação NPK sobre o rendimento do trigo e algumas propriedades químicas do solo. R. Bras. Ci. Solo, 4:31-35, 1980.

RHEINHEIMER, D.; CASSOL, P.C.; KAMINSKI, J \& \& ANGHINONI, I. Fósforo orgânico no solo. In: SANTOS, G.A. \& CAMARGO, F.A.O., eds. Fundamentos da matéria orgânica do sol o: ecossistemas tropicais esubtropicais. Porto Alegre, Genesis, 1999. p.139-158.

RHEINHEIMER, D.S.; GATIBONI, L.C.; KAMINSKI, J .; ROBAINA, A.D.; ANGHINONI, I.; FLORES, J.P.C. \& HORN, D. Situação da fertilidade dos solos no estado do Rio Grande do Sul. Santa Maria. Universidade F ederal de Santa Maria, 2001. 41p. (Boletim Técnico, 2)

RIBEIRO J UNIOR, J .I. Análises estatísticas no SAEG. Viçosa, Universidade Federal de Viçosa, 2001. 301p.

SANCHEZ, P.A.; VILLACHICA, J.H. \& BANDY, D.E. Soil fertility dynamics after clearing a tropical rainforest in Peru. Soil Sci. Soc. Am J ., 47:1171-1178, 1983.

SILVA, M.S.L. \& RIBEIRO, M.R. Influência do cultivo contínuo da cana-de-açúcar nas propriedades químicas de solos argilosos. Pesq. Agropec. Bras., 30:389-394, 1995.

TEDESCO, M.J .; GIANELLO, C.; BISSANI, C.A.; BOHNEN, H. \& VOLKWEISS, S.J . Análise de solo, plantas e outros materiais. 2.ed. Porto Alegre, Universidade Federal do Rio Grande do Sul, 1995. 174p. (Boletim Técnico, 5)

TOGNON, A.A.; DEMATTÊ, J .A.M. \& MAZZA, J .A. Alterações nas propriedades químicas de latossol os roxos em sistemas de manejo intensivos e de longa duração. R. Bras. Ci. Solo, 21:271-278, 1997.

VALE J ÚNIOR, J.F.; SCHAEFER, C.E.R. \& ANDRADE, F.V. Alterações nas propriedades físicas e químicas de uma terra roxa estruturada após a queima e remoção da floresta, com diferentes tempos de cultivo, em Roraima, Amazônia. In: REUNIÃO BRASILEIRA DE MANEJ O E CONSERVAÇÃO DO SOLO E DA ÁGUA, 12., Fortaleza, Sociedade Brasileira de Ciência do Solo/Universidade Federal do Ceará, 1998. p.200-201.

VOLKWEISS, S.J . Química da acidez dos solos. In: SEMINÁRIO SOBRE CORRETIVOS DA ACIDEZ DO SOLO, 2., Santa Maria, Universidade Federal de Santa Maria, 1989. p.738.

WÜNSCHE, W.A.; DENARDIN, J .E.; MIELNICZUK, J .; SCOPEL, I.; SCHNEIDER, P. \& CASSOL, E.A. Projeto integrado de uso e conservação do solo- U m esforço conjunto para a conservação do solo no RS. Trigo e Soja, 51:20-25, 1980. 